\title{
Integral Dose and Dosimetric Comparison of NeoAdjuvant Simultaneous Integrated Boost (SIB) Radiotherapy Technique for Rectal Cancer Using Intensity-Modulated Radiotherapy (IMRT), Volumetric Modulated Arc Therapy (VMAT), and Helical Tomotherapy (HT)
}

\author{
Oztun TEMELLI ${ }^{1}$, Mehmet DEMIRTAS ${ }^{1}$, Berat Tugrul UGURLU ${ }^{1}$, Harika Gozukara BAG ${ }^{2}$ \\ ${ }^{1}$ Department of Radiation Oncology, Inonu University, Faculty of Medicine \\ ${ }^{2}$ Department of Biostatistics, Inonu University, Faculty of Medicine, Malatya, TURKEY
}

\begin{abstract}
The purpose of the present study is to compare the Intensity-Modulated Radiotherapy (IMRT), Volumetric Modulated Arc Therapy (VMAT), Helical Tomotherapy (HT) techniques in rectal cancer. A total of 10 patients, were randomly selected for this study. Three separate plans were made for each patient: IMRT, VMAT and HT. By using the Simultaneous Integrated Boost (SIB) technique, 45 Gy to pelvic lymph nodes, and 50 Gy 25 fractions were prescribed to the rectum and mesorectum. The PTV parameters, Integral dose, Dose Volume Histograms (DVH) and Organ at Risk were evaluated with 3 separate plans. The PTV Dmax, Integral dose was ensured at the lowest level in HT. The D2 was detected at the lowest level in HT, and at the highest level in D98. Although there was no difference between Homogeneity Indices $(\mathrm{HI})$, Conformity Index $(\mathrm{Cl})$ was found to be better in IMRT and VMAT. The total MU and Beam on Time values were found to be high in HT. The bladder, which is one of the risky organs, was provided at the best level in HT, the volume in the bowel was provided in VMAT at the lowest level with 35 Gy, and the 45 Gy volume was provided in IMRT. The healthy tissue volume was 5 Gy and 10 Gy (cc) as the highest in HT, and 20 Gy volume (cc) was high in IMRT. The Mean V10, V20, V30, V40, Dmean values of the pelvic whole bones were higher in $\mathrm{HT}$.
\end{abstract}

Keywords: Rectal Cancer, Integral Dose, Intensity-Modulated Radiotherapy, Volumetric Modulat-ed Arc Therapy, Helical Tomotherapy

\section{ÖZET}

Rektum Kanserinde Neoadjuvan Radyoterapi Uygulamasında SIB (Simultaneous Integrated Boost) tekniği kullanarak Yoğunluk Ayarlı Radyoterapi (YART), Volumetrik Modulated Ark Terapi (VMAT) ve Helikal Tomoterapi (HT) yöntemlerinin Dozimetrik ve Integral Doz Açısından Karşılaştırılması

Bu çalışmanın amacı rektum kanserinde neoadjuvan radyoterapi uygulamasında SIB (Simultaneous Integrated Boost) tekniği kullanarak Yoğunluk Ayarlı Radyoterapi (YART), Volumetrik Modulated Ark Terapi (VMAT) ve Helikal Tomoterapi (HT) yöntemlerinin karşılaştırımasıdır. Bu çalışma için toplam 10 hasta randomize olarak seçildi. Her hasta için IMRT,VMAT ve HT olmak üzere 3 ayrı plan yapıldı. Simultaneous Integrated Boost (SIB) tekniği kullanılarak pelvik lenf nodlarına 45 Gy; rektum ve mezorektuma 50 Gy 25 fraksiyonda reçetelendirildi. PTV parametreleri, Integral doz, Doz volüm histogramları (DVH) ve risk altındaki organlar 3 ayrı planda değerlendirildi.PTV Dmax, Integral doz en düşük HT'de sağlanmıştır. D2 en az HT'de; D98 en yüksek HT'de bulunmuştur. Homojenite indeksi (HI) arasında fark bulunmazken konformite indeksi (CI) IMRT ve VMAT'da daha iyi bulunmuştur.

ORCIDS: Oztun Temelli: 0000-0003-3471-1284 Berat Tugrul Ugurlu: 0000-0001-9521-1609

UHOD Number: 3 Volume: 29 Year: 2019
Mehmet Demirtas: $\quad$ 0000-0001-8308-6601 Harika Gozukara Bag: 0000-0003-1208-4072 
Toplam MU ve ışınlama süreleri ise HT'de yüksek bulunmuştur. Riskli organlardan mesane en iyi HT'de, bağırsak 35 Gy alan hacim en az VMAT'da 45 Gy alan hacim ise IMRT'de sağlanmıștır. Sağlıklı doku 5 Gy ve 10 Gy alan hacim (cc) en çok HT'de, 20 Gy alan hacim (cc) ise IMRT 'de yüksek bulunmuştur. Pelvik tüm kemiklerde ortalama V10, V20, V30, V40, Dmean değeri HT 'de daha yüksek bulunmuştur.

Anahtar Kelimeler: Rektum Kanseri, İntegral doz, Yoğunluk ayarlı radyoterapi, Volumetrik Modulated Ark Tedavi, Helikal Tomoterapi

\section{INTRODUCTION}

Colorectal cancers are the second most prevalent cancer type in the United States. Cancer $2 / 3$ is localized in the column, and $1 / 3$ is localized in the rectum. ${ }^{1}$ Today, surgical approach, and following this, the NeoAdjuvant Chemoradiotherapy, are the standard approaches in local advanced-level rectum cancer (T3-T4 or lymph node positive). ${ }^{2}$

Radiotherapy application may be performed with 3-Dimensional Conformal Radiation Therapy (3DCRT), Intensity-Modulated Radiation Therapy (IMRT), Volumetric Modulated Arc Therapy (VMAT), and Helical Tomotherapy (HT) techniques. Since Planning Target Volume (PTV) is in the form of a horseshoe in rectum cancer, the beamed small intestine volume cannot be protected adequately with 3D Conformal Radiotherapy (3DCRT). ${ }^{3}$

Intensity-Modulated Radiation Therapy (IMRT) is an improved radiotherapy technique, which allows high-dose radiotherapy to the target area by protecting the surrounding tissues. In recent years, its use in rectal cancers has increased. ${ }^{4}$ The IMRT Technique has been shown as a proper option since it decreases the small intestine doses in localized advanced-level rectum cancer. ${ }^{5,6}$ In addition, the IMRT Technique enables giving different doses to different target volumes in the same fraction. This technique is also called Simultaneous Integrated Boost (SIB) technique. With the help of this technique, it is possible to give high-dose to the boost volume by keeping the dose low in the elective radiation areas to which we give low doses. ${ }^{7}$ In a Phase 2 study, the NeoAdjuvant Radiotherapy was applied to 108 patients. The acute and late toxicity was found to be extremely at low levels. It was reported that the SIB technique with an increase in dose might be used safely. ${ }^{8}$
VMAT is an novel form of IMRT, and its use has increased in recent years in rectal cancer thanks to its advantages, such as providing better risky organ doses via gantry rotating while the beam is on and the dose rate is varying, having less total MU, and less treatment time. ${ }^{3}$

Helical Tomotherapy is a novel method and arc-based application of IMRT. During the treatment, gantry rotates $360^{\circ}$ in a constant and fixed speed to apply RT. During the Helical Treatment, while Linac rotates constantly, $360^{\circ}$ is divided into 51 projection angles, and the MLC order changes in each projection. With the help of this rotational movement, it enables target dose conformity and reduces dosages in Organ at Risk (OAR). ${ }^{9}$

The purpose of the present study was to compare the IMRT, VMAT, and HT techniques dosimetrically in NeoAdjuvant rectal cancer in terms of OAR, PTV coverage, and Integral dose.

\section{PATIENTS AND METHODS}

\section{Patient Selection}

The study included a total of 10 patients whom we had previously treated with Pelvic RT in the Tomotherapy Device due to local advanced rectal cancer. The study was approved by the local Ethics Committee in accordance with Helsinki Declaration.

\section{Simulation and Contouring of Targets and OARs}

All patients were asked to drink $500 \mathrm{cc}$ water 30 minutes before; and in supine position, the planned $\mathrm{CT}$ was performed from the L3 vertebra level to femur $1 / 3$ proximal with and without giving contrast at $3 \mathrm{~mm}$ thickness. The images were sent to Velocity Contouring Station (version 2.8.1, the USA). 


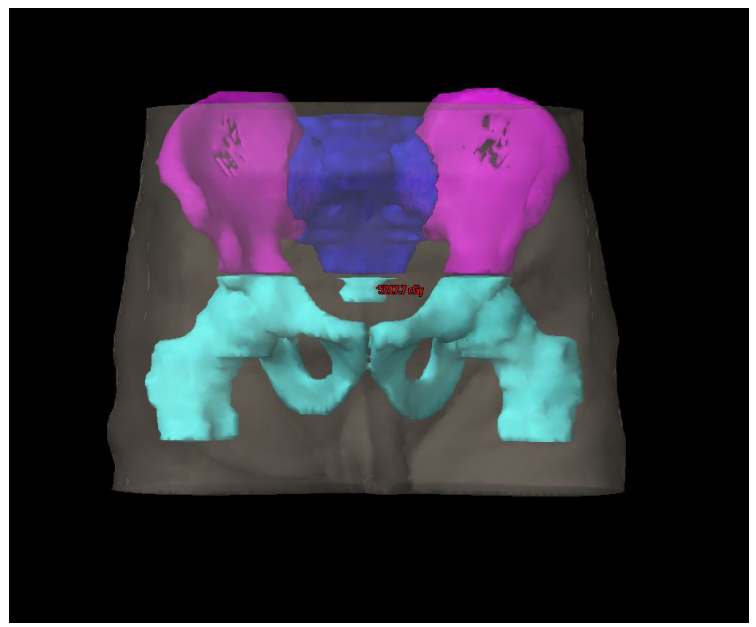

Figure 1. Coronal section illustrating of iliac (pink), lumbosacral (blue) and lower pelvic (cyan) bones

Clinical Target Volume (CTV) and Organ at Risk (OARs) were contoured in line with the RTOG Atlas. ${ }^{10}$ Bladder, bowel bag, femoral heads, whole pelvic bones, ilium, lumbosacral spine, and lower pelvis were defined as the Organs at Risk (OARs). Whole pelvic bones were contoured as all the bone and bone marrows $2 \mathrm{~cm}$ below and above the PTV. Whole pelvic bones contain L5 vertebra, sacrum, ilium, pubic bone, ischium, acetabulum, and proximal femoral head. The body was contoured $3.5 \mathrm{~cm}$ below and above the PTV. When the pelvic bones were contoured, they were divided into 3 sections: ilium (all iliac channels from the tops of the femur heads), lumbosacral spine (L5 vertebra + sacrum), lower pelvis (pubic bone, ischium, acetabulum, proximal femoral head) ${ }^{11}$ (Figure 1). Healty tissues were defined as Body-PTV. OARs dose constrains were determined based on the RTOG 0822 Study, and are shown in Table $1 .{ }^{12}$

\section{Treatment Planning}

PTV was obtained by adding $0.5 \mathrm{~cm}$ margin to the CTV. Prescription dose was determined as 45 Gy at 25 fraction (PTV 1) and 50 Gy at 25 fraction (PTV 2) with Simultaneous Integrated Boost (SIB) technique after dose calculation dose was normalized to cover $95 \%$ of the PTV. A volume of 0.03 cc within any PTV should not receive $>110 \%$ of the prescribed dose. No more than $0.03 \mathrm{cc}$ of PTV will receive $<93 \%$ of its prescribed dose. None of the $0.03 \mathrm{cc}$ or more volumes except for PTV were allowed to receive $>110 \%$ of the prescribed dose of PTV.

In VMAT and IMRT planning, Varian Eclipse planning system (version 13.7- Varian Medical Systems, Palo Alto, the USA) was used; and in HT planning, the Tomotherapy Planning System

\begin{tabular}{|ll|}
\hline Table 1. Dose constrains & \\
\hline Structures & Dose Constraints \\
\hline PTV & $\geq 98 \%$ of PTV receiving $93 \% \geq$ of the prescribed dose \\
& $\geq 10 \%$ of PTV receiving $105 \% \geq$ of the prescribed dose \\
& $\geq 5 \%$ of PTV receiving $110 \% \geq$ of the prescribed dose \\
& None of the PTV volume should receive $115 \% \geq$ of the prescribed dose \\
& $\leq 40 \%$ of bladder receiving $\geq 40$ Gy \\
& $\leq 15 \%$ of bladder receiving $\geq 45$ Gy \\
Bladder & No bladder volume should receive 50 Gy \\
& $\leq 180$ cc of small bowel receiving $\geq 35$ Gy \\
& $\leq 100$ cc of small bowel receiving $\geq 40$ Gy \\
Small Bowel & $\leq 65$ cc of small bowel receiving $\geq 45$ Gy \\
& No small bowel volume should receive 50 Gy \\
& $\leq 40 \%$ of femoral head receiving $>40$ Gy \\
& $\leq 25 \%$ of femoral head receiving $>45$ Gy \\
Femoral head & No femoral head volume should receive 50 Gy
\end{tabular}




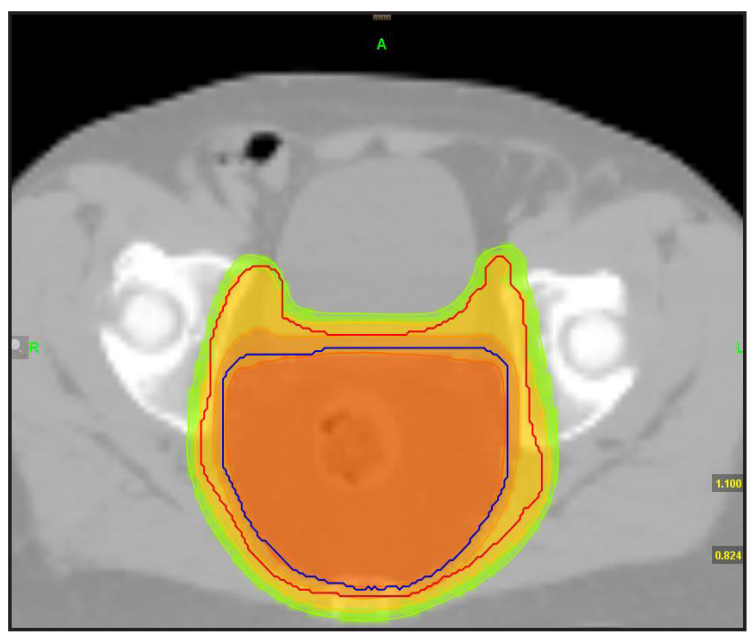

Figure 2a. Isodose curves of 1 patient in transverse section for HT

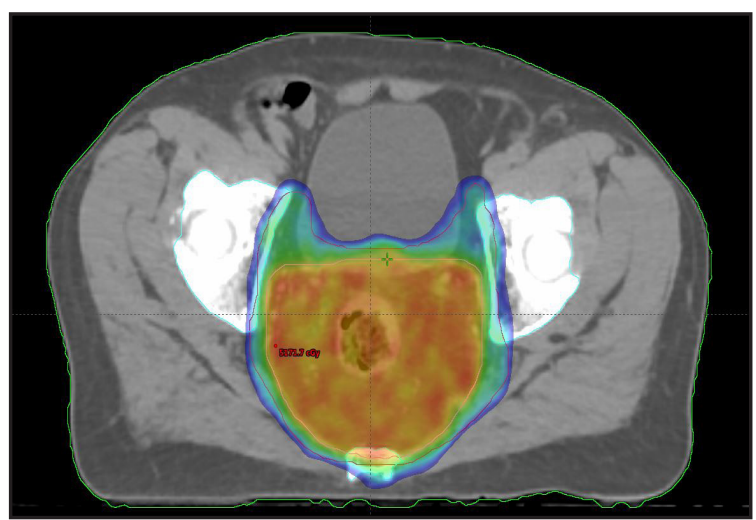

Figure 2c. Isodose curves of 1 patient in transverse section for VMAT (cyan) bones

(Hi-Art Tomotherapy, version 5.1.2, Accuray, Madison, WI, the USA) was used. For IMRT and VMAT plans, the structures contoured at Velocity Contouring Station were transferred to the Eclipse Planning System DICOM (Digital Imaging and Communication in Medicine) format.

In IMRT plans, 7 Coplanar Beams $\left(0^{\circ}-52^{\circ}-104^{\circ}-\right.$ $156^{\circ}-208^{\circ}-260^{\circ}-312^{\circ}$ ) and Sliding Window Technique were used. The Isocenter was determined as the midpoint of the PTV volume. Dose constrains were defined for PTV and OARs.

Anisotropic Analytical Algorithm (AAA) photon dose calculation algorithm was used for IMRT and VMAT plans. Maximum dose rate was $400 \mathrm{MU} /$ min for IMRT plan and $600 \mathrm{MU} / \mathrm{min}$ for VMAT plan. The dose calculation grid was $2.5 \mathrm{~mm}$.

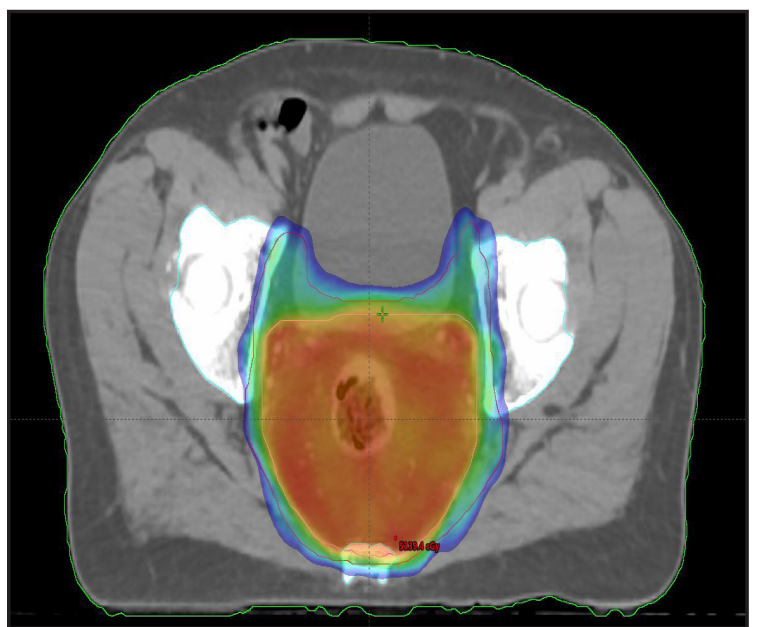

Figure $\mathbf{2 b}$. Isodose curves of 1 patient in transverse section for IMRT

In all VMAT plans, 2 clockwise and 1 counterclockwise arcs were used. Arc rotations were $181^{\circ}-179^{\circ}$ clockwise and $179^{\circ}-181^{\circ}$ counterclockwise. For all plans, the number of MLC apertures were 177 as spaced at every 2 degrees for a full arc. PO (Photon Optimizer version 13.7) algorithm was used for optimized leaf position, dose rate, and gantry speed. The collimator was rotated $30^{\circ}, 90^{\circ}$, and $330^{\circ}$ to reduce overlapping tongue and groove effects.

In IMRT and VMAT techniques, 120-leaf (central 20 -cm of field uses, 0.5 -cm-wide leaves, outer field uses 1-cm-wide leaves) dynamic Multi-Leaf Collimator (MLC) were used. The maximum leaf speed is $2.5 \mathrm{~cm} / \mathrm{s}$.

For HT plans, a field width of $2.5 \mathrm{~cm}$, pitch values of 0.287 , modulation factor of 3 , and fine dose calculation grid was used. 6MV energy was used in all VMAT, IMRT, and HT plans.

\section{Evaluation Tools}

Plan evaluation was performed by examining all CT slides one-by-one and by examining the Dose Volume Histogram (DVHs), isodose curves (Figure 2).

The Homogeneity Index (HI) were calculated as $\mathrm{HI}=\mathrm{D} 2-\mathrm{D} 98 / \mathrm{Dp}$. In this formula, D2 is the minimum dose to $2 \%$ of the target volume, D98 is the minimum dose to the $98 \%$ of the target volume, 


\begin{tabular}{|c|c|c|c|c|c|c|}
\hline Parameter & $\begin{array}{l}\text { IMRT } \\
(\text { Mean } \pm S D)\end{array}$ & $\begin{array}{l}\text { VMAT } \\
(\text { Mean } \pm S D)\end{array}$ & $\begin{array}{l}\text { HT } \\
\text { (Mean } \pm S D)\end{array}$ & $\begin{array}{l}\text { P (IMRT vs } \\
\text { VMAT) }\end{array}$ & $\begin{array}{l}\text { P (VMAT } \\
\text { vs HT) }\end{array}$ & $\begin{array}{l}\text { P (IMRT } \\
\text { vs HT) }\end{array}$ \\
\hline Dmean (Gy) & $5064.8 \pm 8.5$ & $5060 \pm 6.3$ & $5048 \pm 22$ & NS & NS & NS \\
\hline Dmax (Gy) & $5173 \pm 17$ & $5194 \pm 15$ & $5114 \pm 31$ & 0.009 & $<0.001$ & $<0.001$ \\
\hline PTV Integral dose (Gy/L) & $25.44 \pm 8.2$ & $25.41 \pm 8.2$ & $25.12 \pm 8$ & NS & $<0.001$ & $<0.001$ \\
\hline Body Integral dose (Gy/L) & $293.5 \pm 70.7$ & $292.6 \pm 76.5$ & $310.9 \pm 73.9$ & NS & $<0.001$ & $<0.001$ \\
\hline Conformity Index & $0.971 \pm 0.003$ & $0.973 \pm 0.002$ & $0.949 \pm 0.002$ & NS & $<0.001$ & 0.001 \\
\hline Homogeneity Index & $0.03 \pm 0.002$ & $0.03 \pm 0.005$ & $0.02 \pm 0.011$ & NS & NS & NS \\
\hline $\mathrm{MU} / \mathrm{fx}^{*}$ & 1308 & 539 & 6014 & NS & $<0.001$ & $<0.001$ \\
\hline Beam on time/fx (sc) & $238.2 \pm 39.9$ & $230 \pm 4.2$ & $430.9 \pm 50.2$ & NS & $<0.001$ & $<0.001$ \\
\hline PTV 95 (\%) & 5000 & 5000 & 5003 & NS & NS & NS \\
\hline D2* & 5120 & 5117 & 5082 & NS & 0.008 & 0.008 \\
\hline D98* & 4968 & 4967 & 4979 & NS & 0.008 & 0.008 \\
\hline $\begin{array}{l}\text { * Since it is non parametri } \\
\text { NS: not significant }\end{array}$ & redian values & dicated. & & & & \\
\hline
\end{tabular}

and $\mathrm{Dp}$ is the prescribed dose. This is the most commonly used formula in the literature. ${ }^{13}$

The Conformity Index (CI) was calculated as Conformity index RTOG= VRI/TV. (VRI: volume of the reference dose and TV: target volume) ${ }^{14}$

The Integral Dose (ID) was defined as Mean dose (Gy) x Volume (L). ${ }^{15}$

\section{Statistical Analysis}

Analyses were performed using the Statistical Package for Social Science version 22.0 software (SPSS, Chicago, IL, the USA). Data were summarized by mean \pm standard deviation (SD). The Shapiro-Wilk test was used to assess the normality distribution of the data. Normally-distributed data were analyzed by Repeated Measures Analysis of Variance and Bonferroni Post-Hoc Method. The data that were not distributed normally were analyzed with Friedman Test and Bonferroni Adjusted Pairwise Comparison. In all analyses, the significance level was taken as 0.05 .

\section{RESULTS}

The mean PTV volume was found to be $1147 \mathrm{cc}$ (range $855.7-1622$ cc). The mean PTV boost volume was found to be $502 \mathrm{cc}$ (range 275-709 cc).

The PTV coverage and OAR sparing were acceptable for each 3 techniques for 10 patients. The PTV coverage comparison is shown in Table 2.

The Mean Dmax dose was found to be lower than others in HT. The mean CI value was found to be lower than others in HT plans; and the Mean HI was found to be similar. IMRT and VMAT plans were found to be superior to others in terms of CI. The PTV integral dose was found to be lower in HT compared to others, and the Body integral dose was found to be higher in HT compared to others.

The Mean MU was found to be lower in VMAT at a significant level. The Mean beam on time per fraction IMRT and VMATs were found to be significantly lower than the HT at an equal and lower level.

Bowel: 35 Gy intestine volume (cc) was found to be lower in VMAT compared to others, 45 Gy intestine volume (cc) was found to be lower in IMRT and VMAT compared to HT. 
International Journal of Hematology and Oncology

\begin{tabular}{|c|c|c|c|c|c|c|}
\hline & $\begin{array}{l}\text { IMRT } \\
\text { (Mean士SD) }\end{array}$ & $\begin{array}{l}\text { VMAT } \\
\text { (Mean } \pm S D)\end{array}$ & $\begin{array}{l}\text { HT } \\
\text { (Mean } \pm S D)\end{array}$ & $\begin{array}{l}\text { P (IMRT vs } \\
\text { VMAT) }\end{array}$ & $\begin{array}{l}\text { P (VMAT } \\
\text { vs HT) }\end{array}$ & $\begin{array}{l}\text { P (IMRT } \\
\text { vs HT) }\end{array}$ \\
\hline \multicolumn{7}{|l|}{ Bladder } \\
\hline V10 & 100 & 100 & 100 & NS & NS & NS \\
\hline V20* & 100 & 100 & 89.1 & NS & 0.001 & 0.001 \\
\hline V30* & 68.85 & 73.10 & 47.35 & NS & $<0.001$ & $<0.001$ \\
\hline V40 & $35.3 \pm 4.3$ & $33.9 \pm 4.6$ & $30.57 \pm 4.3$ & ns & 0.003 & $<0.001$ \\
\hline V50 & $4.15 \pm 3$ & $4.42 \pm 3.2$ & $3.92 \pm 3.2$ & ns & ns & ns \\
\hline Dmean (cGy) & $3588 \pm 61.9$ & $3626 \pm 55.5$ & $3221 \pm 101$ & ns & $<0.001$ & $<0.001$ \\
\hline $\operatorname{Dmax}^{\star}(\mathrm{cGy})$ & 5136 & 5159 & 5108 & NS & $<0.001$ & NS \\
\hline \multicolumn{7}{|l|}{ Bowel } \\
\hline 35 Gy $(\mathrm{cc})^{*}$ & 147.50 & 117.95 & 136.20 & 0.007 & 0.007 & NS \\
\hline 45 Gy (cc)* & 38.70 & 42.10 & 45.95 & NS & NS & 0.002 \\
\hline \multicolumn{7}{|l|}{ Healthy Tissues } \\
\hline 5 Gy (cc) & $10747 \pm 2596$ & $11133 \pm 2649$ & $12417 \pm 2490$ & 0.005 & $<0.001$ & $<0.001$ \\
\hline 10 Gy (cc) & $8853 \pm 2138$ & $9310 \pm 2338$ & $10415 \pm 2340$ & 0.001 & $<0.001$ & $<0.001$ \\
\hline 20 Gy $(\mathrm{cc})^{*}$ & 4903 & 4403 & 4449 & 0.007 & NS & 0.007 \\
\hline \multicolumn{7}{|l|}{ Pelvic Bones } \\
\hline V10 & $81.02 \pm 1.2$ & $80.9 \pm 1.2$ & $88.06 \pm 1.1$ & NS & $<0.001$ & $<0.001$ \\
\hline V20 & $70.8 \pm 6$ & $68 \pm 6.1$ & $72.7 \pm 5.4$ & 0.003 & $<0.001$ & NS \\
\hline V30 & $46.7 \pm 5.9$ & $46.3 \pm 7.3$ & $50.9 \pm 5.9$ & NS & $<0.001$ & $<0.001$ \\
\hline $\mathrm{V} 40^{*}$ & 21.80 & 20.2 & 29.13 & NS & $<0.001$ & NS \\
\hline V50 & $0.97 \pm 0.7$ & $0.91 \pm 0.6$ & $0.93 \pm 0.8$ & NS & NS & NS \\
\hline Dmean (cGy) & $2758 \pm 165$ & $2700 \pm 192$ & $2915 \pm 174$ & NS & $<0.001$ & $<0.001$ \\
\hline \multicolumn{7}{|c|}{ Femoral Head (Right) } \\
\hline V30 & $6.97 \pm 4.6$ & $11.5 \pm 9.4$ & $13.92 \pm 8.8$ & NS & NS & 0.006 \\
\hline V40* & 0.14 & 0.03 & 0.87 & NS & 0.044 & S \\
\hline Dmax & $4214 \pm 311$ & $4123 \pm 398$ & $4274 \pm 205$ & NS & NS & NS \\
\hline \multicolumn{7}{|c|}{ Femoral Head (Left) } \\
\hline V30 & $8.4 \pm 5.8$ & $12.68 \pm 11$ & $15.3 \pm 8.5$ & NS & NS & 0.009 \\
\hline V40* & 0.06 & 0.2 & 1.47 & NS & NS & 0.013 \\
\hline Dmax & $4163 \pm 346$ & $4248 \pm 262$ & $4320 \pm 185$ & NS & NS & NS \\
\hline \multicolumn{7}{|l|}{ Iliac bones } \\
\hline V10 & $72.16 \pm 4.6$ & $73.2 \pm 5.4$ & $81.54 \pm 4.8$ & NS & $<0.001$ & $<0.001$ \\
\hline V20 & $58.6 \pm 6.3$ & $54.3 \pm 6.2$ & $61.53 \pm 5$ & $<0.001$ & $<0.001$ & NS \\
\hline V30 & $30 \pm 5.7$ & $31.4 \pm 6.5$ & $33.7 \pm 6.3$ & NS & NS & 0.027 \\
\hline V40 & $10.7 \pm 2.3$ & $9.8 \pm 1.9$ & $15.9 \pm 3.4$ & NS & $<0.001$ & $<0.001$ \\
\hline V50* & 0 & 0 & 0 & NS & NS & NS \\
\hline Dmean (cGy) & $2246 \pm 153$ & $2213 \pm 205$ & $2405 \pm 200$ & NS & $<0.001$ & $<0.001$ \\
\hline \multicolumn{7}{|c|}{ Lumbosacral Spine } \\
\hline V10 & $79.7 \pm 8.5$ & $77.8 \pm 8.2$ & $87.49 \pm 7.5$ & 0.033 & $<0.001$ & $<0.001$ \\
\hline V20 & $74.2 \pm 9.4$ & $70.7 \pm 9.4$ & $80.7 \pm 8.2$ & $<0.001$ & $<0.001$ & $<0.001$ \\
\hline V30 & $67.1 \pm 10.4$ & $62.9 \pm 9.6$ & $72.3 \pm 9.5$ & $<0.001$ & $<0.001$ & $<0.001$ \\
\hline V40 & $41.3 \pm 6.2$ & $36.4 \pm 5.8$ & $49.8 \pm 9.5$ & $<0.001$ & $<0.001$ & $<0.001$ \\
\hline V $50^{*}$ & $2.2 \pm 2$ & $2.25 \pm 2$ & $2.2 \pm 2.3$ & NS & NS & NS \\
\hline Dmean (cGy) & $3190 \pm 339$ & $3053 \pm 326$ & $3439 \pm 353$ & $<0.001$ & $<0.001$ & $<0.001$ \\
\hline \multicolumn{7}{|l|}{ Lower pelvis } \\
\hline $\mathrm{V} 10^{\star}$ & 70.4 & 81.6 & 91.2 & NS & NS & $<0.001$ \\
\hline V20* & 55.6 & 55.7 & 58.6 & NS & NS & 0.014 \\
\hline V30 & $27 \pm 8.2$ & $30.9 \pm 13.9$ & $32.14 \pm 8.3$ & NS & NS & 0.006 \\
\hline V40* & 11.3 & 9.95 & 14.6 & NS & $<0.001$ & $<0.001$ \\
\hline V50* & 0.30 & 0.25 & 0.15 & NS & NS & NS \\
\hline Dmean (cGy) & $2137 \pm 285$ & $2299 \pm 395$ & $2425 \pm 301$ & 0.028 & 0.033 & $<0.001$ \\
\hline
\end{tabular}


Bladder: The Mean Dmean, Dmax, V20, V30, V40 doses were found to be lower in the HT; and V50 doses were found to be equal in all three of them.

Pelvic Whole Bones: The Mean V10, V20, V30, V40, Dmean values were found to be higher in HT; the V20 value was found to be at the lowest level in VMAT, and similar in IMRT and VMAT.

Iliac Bones: The Mean V10, V20, V30, V40, and Dmean values were found to be significantly highest in HT.

Lumbosacral Bones: The Mean V10, V20, V30, $\mathrm{V} 40$, and Dmean values were found to be significantly highest in HT and at the lowest level in VMAT.

Lower Pelvic Bones: The Mean V10, V20, V30 values were found to be significantly highest in HT and lowest in IMRT. The V40 value was found to be higher in HT, and at the lowest level in VMAT. The Dmean value was found to be different in 3 techniques. It was at the highest level in HT and at the lowest level in IMRT.

Right-Left Femoral Head: The Mean V30 values were found to be significantly lowest in IMRT. The Mean V40 values were found to be lower in the right femur head in VMAT, and lower in the left femur head in IMRT. The Dmax dose was, albeit not statistically significant, found to be lower in VMAT in the right femur head and lower in IMRT in the left femur head.

Healthy Tissues: The 5 Gy and 10 Gy volume (cc) was found at the highest level in HT and at the lowest level in the IMRT. The 20 Gy volume (cc) was found to be high in IMRT, and similar in the other two. The OARs comparison is shown in Table 3.

\section{DISCUSSION}

Various randomized studies have shown the importance of NeoAdjuvant RT in Stage 2-3 rectum cancer. In a Swedish Rectal Cancer Trial, it was shown that preoperative RT alone ensured $17 \%$ (9\% vs. $26 \%$ ) advantage in local recurrence when compared to surgery alone, and $8 \%$ (38\% vs. $30 \%$ ) advantage in Overall Survival (OS). ${ }^{16}$ However, Grade 3 toxicity was observed after chemoradiotherapy. In the German Rectal Cancer Study Group, 27\% grade $\geq 3$ acute toxicity and $14 \%$ grade $\geq 3$ late toxicity were reported. In the study that was conducted by Braendengen et al., acute toxicity was reported as $28 \%$, and late toxicity was reported as $17 \% .{ }^{17,18}$ The 3DCRT was used in both studies. Because of these side effect rates, new treatment modalities have been brought to the agenda. With the help of IMRT, VMAT, and HT, healthy tissues can be protected better, and dose escalation becomes possible. ${ }^{8,19}$

In the study that was conducted by Guerrero et al., the intestine doses were found to be lower in IMRT compared to 3DCRT. ${ }^{5}$ In another study, the bladder and small intestine doses were found to be lower in IMRT. In terms of the radiated body volume, although V5-10 values were not significant, they were found to be lower in 3DCRT. The V20 value was found to be lower in IMRT $(p=0.05) .{ }^{6}$ In rectum cancer, the Arc Therapy was first described by Duthoy et al. In a previous study, the IntensityModulated Arc Therapy (IMAT) was compared with 3DCRT in a dosimetric way in 7 patients. The inhomogeneity, the mean small intestine dose and the Integral Dose were found to be lower in IMAT. ${ }^{20}$ Richetti et al. conducted a study and applied Arc Therapy to 25 patients who had local advanced-stage rectum cancer, and compared their results with those of 20 patients who had similar characteristics and who underwent 3DCRT. Arc Therapy provided better CI, lower maximum doses, femur protection at significant levels, and less integral and mean doses were ensured in healthy tissues. Clinically, it was determined that $40 \%$ of the patients had Grade 1-2 diarrhea, and $8 \%$ had Grade 3 diarrhea in Arc Therapy; however, these rates were found to be $45 \%$ and $5 \%$, respectively in 3DCRT. ${ }^{21}$

The comparison of IMRT and VMAT was shown in the study that was conducted by Cilla et al. In this study, the 3DCRT, IMRT, and VMAT were compared. In VMAT plans, small intestine doses were found to be lower when compared to 3DCRT; and no difference was detected between IMRT. The bladder V30 value was found to be lower in VMAT compared to 3DCRT. Total MU and delivery times were found to be lower in VMAT 
compared to IMRT. ${ }^{3}$ In our study, the intestinal volume 35 Gy in VMAT was found to be lower compared to IMRT (117 cc vs. $147 \mathrm{cc}$ ). No differences were detected in bladder doses and total MU (539 vs. 1308 ), and beam-on time periods (230 vs 238 ) were, albeit not statistically statistic, found to be lower compared to VMAT and IMRT. In the study that was conducted by Shang et al., IMRT, SingleArc VMAT, and Double-Arc VMAT were compared in 15 patients who had rectal cancer. Lower maximum dose, higher minimum dose, more homogeneous PTV dose distribution, and better CI were obtained in DA-VMAT. In terms of risky organs, on the other hand, the small bowel Dmean, $\mathrm{D} 2 \%, \mathrm{~V} 15, \mathrm{~V} 30$ values were found to be higher in VMAT. The IMRT was similar to DA-VMAT for bladder; and Dmean, V40, V50 doses were higher in SA-VMAT compared to IMRT. The Dmean and D10 values for femoral heads were found to be higher in VMAT. The V20 values for healthy tissues were lower in VMAT compared to IMRT, and the V5 and V10 values were higher compared to IMRT. Total MU and treatment delivery time was found to be lower in VMAT. ${ }^{19}$ In our study, 3 Arcs were used, and the MU and beam-on time values were determined to be higher than those reported by Shang et al. The $5 \mathrm{~Gy}$ and $10 \mathrm{~Gy}$ volumes of the healthy tissues were found to be higher in VMAT and 20 in IMRT, which is consistent with the study that was conducted by Shang et al.

In a study, which compared Helical Therapy with 3 DCRT in rectum cancer, 12 patients were planned to receive preoperative short-course $25 \mathrm{~Gy} / 5 \mathrm{fx}$. Higher mean target, lower HI, and better CI were provided in HT. The mean radiation dose of the risky organs was also found to be better in $\mathrm{HT}^{22}$ In the study of Lin et al., the HT, VMAT, and IMRT plans were compared in different simulated positions in rectum cancer cases. When IMRT was compared in supine position with VMAT, better CI and HI were obtained in VMAT plan. When IMRT was compared with HT, better CI, and HI doses, low bladder mean dose, V34.98, V40 doses, lower femoral head mean dose, and V30-V40 doses were obtained in HT. In the HT and VMAT comparison, better CI, HI, lower bladder mean dose, V34.98, $\mathrm{V} 40$, and femur mean doses were obtained in HT compared to VMAT. When the supine and prone positions were compared, no differences were detected with the three techniques except for the lower bladder V34.98 in the supine position with HT. ${ }^{23}$ In our study, Dmax, D2 and D98 were provided with HT. Although there were no differences in homogeneity index, the CI was found to be lower in HT than in others. The MU and beam on time values were higher at a significant level in HT. The bladder doses were obtained better in HT; however, intestinal V35 Gy (cc) doses were obtained as the best in VMAT, and healthy tissue 5 Gy and 10 Gy volume was obtained at the lowest level in IMRT, and 20 Gy volume was obtained at the lowest level in IMRT.

The integral dose is the total energy that is absorbed by the body, and is calculated according to the mean organ density. ${ }^{24}$ In our study, the PTV2 integral dose was found to be lower in HT. This is due to more homogeneous dose achieved by HT. Since the larger treated area in craniocaudal direction causes undesired dose at the edges of target region, the total body integral dose was higher in HT. Another reason is taught to be the Compton scattering contribution. ${ }^{25}$

Pelvic Radiotherapy can cause hematological toxicities. More than half of the entire Bone Marrow (BM) are found in the pelvis, including os coxae, sacrum, proximal femora, and lower lumbar spine. Bone marrow activity decreases after pelvic RT, and Bone Marrow regeneration varies according to the radiation dose. Decreasing the dose of the BM may decrease the chemoradiotherapy toxicity, and improve the administration of the chemotherapy enabling improved delivery; and thus, this also improves the effectiveness of the treatment. ${ }^{11}$ In our study, whole pelvic bones could be protected at the best level with VMAT, iliac bones could receive the highest amount of dose with HT, the lumbosacral spine could receive the highest radiation in HT, and the lowest in VMAT, and lower pelvis could receive the highest amount of radiation with HT. Femoral heads, on the other hand, received extremely low doses in all 3 techniques; however, they received the highest amount of dose in HT. 


\section{Conclusion}

In our study, the 3 techniques were found to be suitable in terms of OARs and planningcriteria. Since Cone Beam CT (CBCT) or MV CT is performed before the treatment, IGRT is performed without problems. In our routine clinical practice, these patients are treated in HT. However, in patients who have problems in staying in the device for a long time, in patients who have fear of entering in aclosed gantry, and in patients who have high hematotoxicity risk, the treatment may be performed with other techniques as well.

\section{REFERENCES}

1. Siegel RL, Miller KD, Jemal A. Cancer statistics, 2015. CA Cancer J Clin 65: 5-29, 2015.

2. Wang S, Hathout L, Malhotra U, et al. Decision-Making Strategy for rectal cancer management using radiation therapy for elderly or comorbid patients. Int J Radiat Oncol Biol Phys 100: 926-944, 2018.

3. Cilla S, Caravatta L, Picardi V, et al. Volumetric modulated arc therapy with simultaneous integrated boost for locally advanced rectal cancer. Clin Oncol 24: 261-268, 2012.

4. Reyngold M, Niland J, Veer A, et al. Trends in intensity modulated radiation therapy use for locally advanced rectal cancer at National Comprehensive Cancer Network centers. Adv Radiat Oncol 3: 34-41, 2018.

5. Guerrero Urbano MT, Henrys AJ, Adams EJ, et al. Intensitymodulated radiotherapy in patients with locally advanced rectal cancer reduces volume of bowel treated to high dose levels. Int J Radiat Oncol Biol Phys 65: 907-16, 2006.

6. Arbea L, Ramos L, Monge R.M, et al. Intensity-modulated radiation therapy (IMRT) vs. 3D conformal radiotherapy (3DCRT) in locally advanced rectal cancer (LARC): dosimetric comparison and clinical implications. Radiat Oncol 5: 17, 2010.

7. Dogan N, King S, Emami B, et al. Assessment of different IMRT boost delivery methods on target coverage and normak tissue sparing. Int J radiat Oncol Biol Phys 57: 1480-1491, 2003.

8. Engels B, Tournel K, Everaert H, et al. Phase II study of preoperative helical tomotherapy with a simultaneous integrated boost for rectal cancer. Int J Radiat Oncol Biol Phys 83: 142148, 2012.

9. Gani Z, Altundag I. Tomotherapy. Turkiye Klinikleri J Radiat Oncol-Special Topics 2: 157-62, 2016.
10. Myerson RJ, Garofalo MC, El Naqa I, et al. Elective clinica target volumes for conformal therapy in anorectal cancer: a radiation therapy oncology group consensus panel contouring atlas. Int J Radiat Oncol Biol Phys 74: 824-830, 2008.

11. Mell, Loren K. et al. Dosimetric predictors of acute hematologic toxicity in cervicalcancer patients treated with concurrent cisplatin and intensity-modulated pelvic radiotherapy. International Journal of Radiation Oncol Biology Phys 66: 1356-1365, 2006

12. Hong TS, Moughan J, Garofalo MC, et al. A phase 2 study of preoperative chemoradiation therapy using intensity modulated radiation therapy in combination with capecitabine and oxaliplatin for patients with locally advanced rectal cancer. Int J Radiat Oncol Biol Phys 93: 29-36, 2015.

13. Kataria T, Sharma K, Subramani $V$, et al. Homogeneity Index: An objective tool for assessment of conformal radiation treatments. J Med Phys. 37: 207-213, 2012.

14. Feuvret Lioc, Noel G, Mazeron JJ, Bey P. Conformity Index: a review, Int J Radiat Oncol Biol Phys 64: 333-342, 2006.

15. Aoyama $\mathrm{H}$, Westerly DC, Mackie TR, et al. Integral radiation dose to normal structures with conformal external beam radiation. Int J Radiat Oncol Biol Phys 64: 962-7, 2006.

16. Folkesson J, Birgisson H, Pahlman L, et al. Swedish Rectal Cancer Trial: long lasting benefits from radiotherapy on survival and local recurrence rate. J Clin Oncol 23: 5644-5650, 2005.

17. Sauer R, Becker H, Hohenberger W, et al. Preoperative versus postoperative chemoradiotherapy for rectal cancer. N Engl J Med 351: 1731-1740, 2004.

18. Braendengen M, Tveit KM, Berglund A, et al. Randomized phase III study comparing preoperative radiotherapy with chemoradiotherapy in nonresectable rectal cancer. J Clin Oncol 26: 3687-3694, 2008.

19. Shang J, Kong W, Wang Y,et al. VMAT planning study in rectal cancer patients. Radiat Oncol 9: 219, 2014.

20. Duthoy W, De Gersem W, Vergote K, et al. Clinical implementation of intensity- modulated arc therapy (IMAT) for rectal cancer. Int J Radiat Oncol Biol Phys 60: 794-806, 2004.

21. Richetti A, Fogliata A, Clivio A, et al. Neo-adjuvant chemoradiation of rectal cancer with volumetric modulated arc therapy: summary of technical and dosimetric features and early clinical experience. Radiat Oncol 5: 14, 2010.

22. Yu Mina, Jang Hong Seok, Jeon Dong Min, et al. Dosimetric evaluation of Tomotherapy and four-box field conformal radiotherapy in locally advanced rectal cancer. Radiat Oncol $J$ 31: 252-259, 2013.

23. Lin JC, Tsai JT, Chen LJ, et al. Compared planning dosimetry of TOMO, VMAT and IMRT in rectal cancer with different simulated positions. Oncotarget 8: 42020-42029, 2017. 
International Journal of Hematology and Oncology

24. Shi Chengyu, Peñagarícano Jose, Papanikolaou Niko. Comparison of IMRT treatment plans between Linac and Helical Tomotherapy based on integral dose and inhomogeneity index. Med Dosim 33: 215-221, 2008.

25. Wiezorek T, Schwahofer A, Schubert K. The influence of different IMRT techniques on the peripheral dose a comparison between sMLM-IMRT and Helical Tomotherapy. Strahlenther Onkol 185: 696-702, 2009.

\section{Correspondence:}

Dr. Oztun TEMELLI

Inonu Universitesi Tip Fakultesi

Radyasyon Onkolojisi Anabilim Dali

Battalgazi

MALATYA / TURKEY

Fax:(+90-422) 3410728

email: oztun.temelli@inonu.edu.tr 